\title{
Comparison of Forced and Slow Vital Capacity Maneuvers in Defining Airway Obstruction
}

\author{
Nikhil A Huprikar, Andrew J Skabelund, Valerie G Bedsole, Tyson J Sjulin, Asmita V Karandikar, \\ James K Aden, and Michael J Morris
}

\begin{abstract}
BACKGROUND: Obstructive lung disease is diagnosed by a decreased ratio of $\mathrm{FEV}_{1}$ to the vital capacity (VC). Although the most commonly used VC is FVC, American Thoracic Society guidelines suggest alternative VCs, for example, slow VC (SVC), may offer a more-accurate evaluation of breathing capacity. There is recent evidence that using only $\mathrm{FEV}_{1} / \mathrm{FVC}$ underrecognizes obstruction in subjects at high risk and who are symptomatic. Previous studies have indicated that healthy individuals show a minimum difference between FVC and SVC; however, testing of individuals with asthma and who are symptomatic indicates that SVC can be markedly larger than FVC. OBJECTIVE: To evaluate the differences among SVC, FVC, and SVC-based measurements in the diagnosis of symptomatic obstructive lung disease. METHODS: A retrospective analysis was performed of spirometry and plethysmography measurements from studies conducted between 2011 to 2015. We established a pulmonary function database that incorporated predictive equations from the National Health and Nutrition Examination Survey III (NHANES III). The SVC to FVC difference was calculated. $\mathrm{FEV}_{1} / \mathrm{SVC}$ was compared with $\mathrm{FEV}_{1} / \mathrm{FVC}$ by using NHANES III lower limit of normal values. RESULTS: A total of 2,710 studies with 2,244 subjects were reviewed. Spirometric obstruction, as defined by NHANES III, was identified in $26.1 \%$ of the studies (707/ 2,710). The mean ( \pm SD) difference between SVC and FVC was $375.0 \pm 623.0 \mathrm{~mL}$ and $258.8 \pm 532.5 \mathrm{~mL}$ in those with and those without obstruction, respectively. Subgroup and multivariate analysis demonstrated age, body mass index, and $\mathrm{FEV}_{1}$ associated contributions to the difference between SVC and FVC. By using $\mathrm{FEV}_{1} / \mathrm{SVC}$, the prevalence of obstruction increased from 26.1 to $45.0 \%(1,219 / 2,710)$ and identified 566 additional studies of subjects with obstruction. Fifty-four percent of the subjects with newly-identified obstructive lung disease (305/566) had smoking histories, and $67.4 \%(345 / 512)$ received medications for obstructive lung disease. CONCLUSIONS: The isolated use of FVC-based diagnostic algorithms did not recognize individuals with symptomatic obstructive lung disease. Recognizing the difference between SVC and FVC measurements in subjects will improve testing and diagnosis of obstructive lung disease. Key words: airway obstruction; COPD; forced vital capacity; obstructive lung disease; slow vital capacity; spirometry. [Respir Care 2019;64(7):786-792. (C) 2019 Daedalus Enterprises]
\end{abstract}

\section{Introduction}

Obstructive lung disease is characterized by airway inflammation and bronchospasms that limit expiratory air

\footnotetext{
Mr Huprikar, Mr Sjulin, and Ms Karandikar are affiliated with the Pulmonary/Critical Care Service, Brooke Army Medical Center, Joint Base San Antonio (JBSA) Fort Sam Houston, Texas. Mr Skabelund is affiliated with the Pulmonary/Critical Care Service, Wilford Hall Ambulatory Surgery Center, Lackland Air Force Base, Texas. Ms Bedsole is affiliated with the Internal Medicine Residency, Brooke Army Medical Center,
}

flow. COPD is a leading cause of mortality around the world, and symptomatic obstructive lung disease is a frequent cause of physician encounters and utilization of health-care resources. ${ }^{1}$ The American Thoracic Society

\footnotetext{
JBSA Fort Sam Houston, Texas. Mr Aden and Dr Morris are affiliated with the Graduate Medical Education, Brooke Army Medical Center, JBSA Fort Sam Houston, Texas.

Dr Morris discloses relationships with Vyaire and Janssen Pharmaceuticals. The remaining authors have disclosed no conflicts of interest.
} 
1994 guidelines ${ }^{2}$ standardized the diagnosis of obstruction by using $\mathrm{FEV}_{1} / \mathrm{FVC}$. However, the use of $\mathrm{FEV}_{1} / \mathrm{FVC}$ is noted to have significant limitations. Studies demonstrated that inspiratory vital capacity (VC) and slow VC (SVC) measurements are larger than FVC measurements, with $\mathrm{VC}$ measurements having a flow-dependence. ${ }^{3,4}$ This flowdependence is suggested to be more pronounced in subjects with COPD, which results in a truncation of expiratory volume in forced maneuvers. ${ }^{5}$ In acknowledging these limitations, the revised 2005 American Thoracic Society (ATS)/European Respiratory Society (ERS) guidelines ${ }^{6}$ note that alternative $\mathrm{VC}$ measurements may improve the diagnostic accuracy of pulmonary function tests; however, the clinical application of these VC measurements has been limited.

Subjects at high risk for obstructive lung disease can be symptomatic despite having a preserved $\mathrm{FEV}_{1} / \mathrm{FVC}$, which questions the accuracy of $\mathrm{FEV}_{1} / \mathrm{FVC}$ for the diagnosis of obstructive lung disease. ${ }^{7,8}$ Results of previous studies showed that using $\mathrm{FEV}_{1} / \mathrm{SVC}$ does increase the prevalence in diagnostic testing for obstructive lung disease; however, systematic evaluation regarding incorporation of alternative VC measurements has not previously been conducted. ${ }^{9-11}$ It has been hypothesized that SVC can identify subjects with symptomatic obstructive lung disease and a preserved $\mathrm{FEV}_{1} / \mathrm{FVC}$. The objective of this study was to determine if plethysmography-based SVC measurements can supplement the spirometry-based diagnosis of obstructive lung disease and to ascertain the utility of applying SVC to clinical practice.

\section{Methods}

This study was submitted and approved by the Brooke Army Medical Center Institutional Review Board (C.2017.004d). A retrospective analysis of pulmonary function test (PFT) studies completed in our pulmonary function laboratory between 2011 and 2015 was conducted. Completed spirometry with plethysmography studies of subjects ages $\geq 18 \mathrm{y}$, with a weight $>80 \mathrm{lbs}(36.3 \mathrm{~kg})$ and height $>45$ inches $(114.3 \mathrm{~cm})$ were eligible for inclusion. Only pre-bronchodilator values were analyzed to maintain

\footnotetext{
The view(s) expressed herein are those of the authors and do not reflect the official policy or position of Brooke Army Medical Center, the U.S. Army Medical Department, the U.S. Army Office of the Surgeon General, the Department of the Army and Department of Defense or the U.S. government.
}

Correspondence: Nikhil A Huprikar, Pulmonary/Critical Care Service (MCHEZDM-P), Brooke Army Medical Center, 3551 Roger Brooke Drive, JBSA Fort Sam Houston, TX 78234. E-mail: nikhil.a.huprikar.mil@mail.mil.

DOI: $10.4187 /$ respcare.06419

\section{QUICK LOOK}

\section{Current knowledge}

The current guidelines propose incorporating the largest vital capacity measurement in the diagnosis of obstruction rather than defaulting to FVC; however, the literature has insufficiently described the expected alternative vital capacity values. Exclusive use of FVCbased diagnostic algorithms is known to underrecognize individuals with symptoms.

\section{What this paper contributes to our knowledge}

The routine use of SVC to FVC difference or $\mathrm{FEV}_{1} /$ SVC improved identification of patients with obstructive lung disease. Recognition of differences between FVC and SVC may allow for earlier detection of disease and improved treatment outcomes.

uniformity because bronchodilator testing was not routinely performed in all the subjects. All spirometric- and plethysmography-based measurements were conducted by using either Vmax (CareFusion, Yorba Linda, California) or Medgraphics (MCG Diagnostics, Saint Paul, Minnesota) diagnostic equipment. Testing protocols and calibration were conducted in accordance with the 2005 ATS guideline recommendations. ${ }^{6}$ Plethysmography testing was conducted after spirometry-based testing by using the same equipment and standard operating procedures.

Demographic information associated with each PFT was entered into established reference equations from the National Health and Nutrition Examination Survey III ${ }^{12}$ to calculate predicted and lower limit of normal reference values for $\mathrm{FEV}_{1}, \mathrm{FVC}$, and $\mathrm{FEV}_{1} / \mathrm{FVC} .{ }^{12}$ These predicted values were added to our pulmonary function database. A diagnosis of obstructive lung disease was established based on $\mathrm{FEV}_{1} / \mathrm{FVC}<\mathrm{FEV}_{1}$ to lower limit of normal FVC ratio. We compared actual versus predicted $\mathrm{FEV}_{1}$ measurements, grading the percent of predicted $\mathrm{FEV}_{1}$ based on American Thoracic Society/European Respiratory Society 2005 guidelines. ${ }^{6}$ We then characterized $\mathrm{FEV}_{1}$ severity based on previously established markers of mild impairment characterized as an $\mathrm{FEV}_{1}$ of $>70 \%$ predicted; moderate, ranging from 60 to $69 \%$ predicted; moderately severe, categorized as $50-59 \%$ predicted; severe as ranging from 35 to $49 \%$ predicted $\mathrm{FEV}_{1}$; and very severe as $<35 \% .{ }^{6}$ In addition, we placed those individuals with an $\mathrm{FEV}_{1}$ of $>90 \%$ predicted into a normal $\mathrm{FEV}_{1}$ category.

To quantify the relationship between FVC from spirometry and SVC from plethysmography, we calculated the difference between SVC and FVC values in $\mathrm{mL}$ and 
$\mathrm{FEV}_{1} / \mathrm{SVC}$ by using the comparison of $\mathrm{FEV}_{1} / \mathrm{SVC}<\mathrm{FEV}_{1}$ to lower limit of normal FVC ratio to diagnose the presence of obstruction. Clinical evaluation of the specified patient populations was conducted retrospectively through electronic medical record review. Information regarding demographics, smoking history, pulmonary diagnoses to include obstructive and interstitial lung diseases, active pulmonary symptoms, and medication prescriptions for lung diseases were recorded.

Mean $\pm \mathrm{SD}$, and standard error were used as summary statistics for continuous variables. Differences in means were analyzed by using the Student $t$ test, analysis of variance, and Wilcoxon test. Multivariate analysis to determine the difference between SVC and FVC was conducted by using variables of sex, presence of obstruction, $\mathrm{FEV}_{1}$ (in L), age, and body mass index (BMI). Significance was established when $P$ values were $<.05$. The multivariate and statistical analyses were performed by using JMP (SAS Institute, Cary, North Carolina) and SPSS v 22.0 (IBM, Armonk, New York).

\section{Results}

\section{Demographics and Pulmonary Function Tests}

Of the 6,226 eligible pulmonary function studies available, 3,516 were removed due to incomplete data. The remaining 2,710 studies from 2,244 unique subjects were included in the analysis. The study population was predominantly white $(70.6 \%)$, male $(58.0 \%)$ with a mean age of $59.0 \mathrm{y}$, and a mean BMI of $28.0 \mathrm{~kg} / \mathrm{m}^{2}$. The baseline demographic data are shown in Table 1. By using National Health and Nutrition Examination Survey III reference equations, ${ }^{12}$ spirometric obstruction was identified in 707 of the studies (26.1\%). Further spirometric details, based on sex, the presence of obstruction, and $\mathrm{FEV}_{1}$ severity are present in Table 2.

\section{Difference Between SVC and FVC}

The mean \pm SD difference between SVC and FVC was $289.0 \pm 560.0 \mathrm{~mL}$. The mean $\pm \mathrm{SD}$ difference between SVC and FVC for individuals with and those without obstructive spirometry was $375.0 \pm 623.0 \mathrm{~mL}$ and $258.8 \pm 532.5 \mathrm{~mL}$, respectively (Table 1 ). The difference between SVC and FVC variability across the cohort is presented in Figure 1A. When categorized based on BMI, the subjects with obstruction seemed to have a more uniform difference between SVC and FVC whereas the subjects without obstruction had an increase in the difference between SVC and FVC with an increasing BMI (Fig. 1B).

In both subjects with obstruction and subjects without obstruction, there was an increase in the difference between SVC and FVC with worsened $\mathrm{FEV}_{1}$ severity (Fig.
Table 1. Demographic Chart of the Entire Cohort

\begin{tabular}{lc}
\hline \hline \multicolumn{1}{c}{ Demographic } & Value \\
\hline Total studies, no. & 2,710 \\
Males, $n(\%)$ & $1,573(58.0)$ \\
Age, mean \pm SD y & $59.0 \pm 15.4$ \\
BMI, mean \pm SD kg/m ${ }^{2}$ & $28.0 \pm 7.0$ \\
Race, $n(\%)$ & \\
White & $1,913(70.6)$ \\
African American & $431(15.9)$ \\
Hispanic & $355(13.1)$ \\
Asian & $11(0.4)$ \\
Obstructed studies & 707 \\
Studies, no. & $427 / 280$ \\
Males/females, $n$ & $59.4 \pm 16.6$ \\
Age, mean \pm SD y & $27.1 \pm 5.6$ \\
BMI, mean \pm SD kg/m ${ }^{2}$ & $375.0 \pm 623.0$ \\
Difference between FVC and SVC, & \\
$\quad$ mean \pm SD mL & \\
Non-obstructed studies & 2,003 \\
Studies, no. & $1,146 / 857$ \\
Males/females, $n$ & $56.8 \pm 16.7$ \\
Age, mean \pm SD y & $29.0 \pm 5.8$ \\
BMI, mean \pm SD kg/m ${ }^{2}$ & $258.8 \pm 532.5$ \\
Difference between FVC and SVC, & \\
mean \pm SD mL & \\
\hline BMI $=$ body mass index & \\
SVC $=$ slow vital capacity & \\
\hline
\end{tabular}

1C). When stratified based on age, the difference between SVC and FVC also increased with age (Fig. 1D), with a mild decrease in the mean difference in subjects ages $>80 \mathrm{y}$. A Student $t$ test was conducted between the cohorts with obstruction and cohorts without obstruction for each subgroup with statistically significant differences present in BMI and some age subcategories, but there were no differences in $\mathrm{FEV}_{1}$ disease severity subgroups. A multivariate regression analysis was conducted to evaluate predictive markers for the difference between SVC and FVC. Statistically significant variables included sex, age, BMI, and $\mathrm{FEV}_{1}(\mathrm{~mL})$, and the presence of obstruction. The associated weighting and predictive equation are listed in Table 3.

\section{$\mathrm{FEV}_{1} / \mathrm{SVC}$ Based Obstruction}

The 2005 ATS/ERS guidelines ${ }^{6}$ recommend using the largest VC to identify subjects with obstructive lung disease. Use of $\mathrm{FEV}_{1} / \mathrm{SVC}$ instead of the $\mathrm{FEV}_{1} / \mathrm{FVC}$ increased in the prevalence of obstruction from 707 of 2,710 studies (26.1\%) to 1,219 of 2,710 (45.0\%); 54 of 2,710 studies (2.0\%) had obstruction based solely on an $\mathrm{FEV}_{1} / \mathrm{FVC}$, and $653(24.1 \%)$ studies had obstruction based on both $\mathrm{FEV}_{1} / \mathrm{SVC}$ and $\mathrm{FEV}_{1} / \mathrm{FVC}$. Of the studies, 1,437 of 
Table 2. Spirometric and Demographic Details of Obstructed and Non-Obstructed Cohorts Based on Sex and FEV Severity $_{1}$

\begin{tabular}{|c|c|c|c|c|}
\hline \multirow{2}{*}{$\begin{array}{l}\mathrm{FEV}_{1} \text { Severity Categories and } \\
\text { Associated Characteristics }\end{array}$} & \multicolumn{2}{|c|}{$\begin{array}{l}\text { Obstructed Studies } \\
\quad \text { (707 studies) }\end{array}$} & \multicolumn{2}{|c|}{$\begin{array}{l}\text { Non-Obstructed Studies } \\
\quad(2,003 \text { studies })\end{array}$} \\
\hline & Males & Females & Males & Females \\
\hline \multicolumn{5}{|l|}{ Normal/mild impairment* } \\
\hline Studies, no. & 127 & 66 & 886 & 605 \\
\hline Age, mean \pm SD y & $51.5 \pm 18.5$ & $51.1 \pm 16.4$ & $53.4 \pm 17.6$ & $56.6 \pm 16.2$ \\
\hline $\mathrm{BMI}$, mean $\pm \mathrm{SD} \mathrm{kg} / \mathrm{m}^{2}$ & $27.0 \pm 3.8$ & $25.4 \pm 4.3$ & $28.9 \pm 4.4$ & $27.8 \pm 6.1$ \\
\hline $\mathrm{FEV}_{1}$, mean $\pm \mathrm{SD} \%$ predicted & $82.2 \pm 8.8$ & $84.3 \pm 9.1$ & $87.9 \pm 12.0$ & $88.6 \pm 13.1$ \\
\hline $\mathrm{FEV}_{1} / \mathrm{FVC}$, mean $\pm \mathrm{SD} \%$ & $64.9 \pm 5.9$ & $66.5 \pm 5.0$ & $77.0 \pm 4.6$ & $77.6 \pm 4.5$ \\
\hline \multicolumn{5}{|l|}{ Moderate impairment $\dagger$} \\
\hline Studies, no. & 80 & 47 & 137 & 135 \\
\hline Age, mean \pm SD y & $60.1 \pm 16.5$ & $60.8 \pm 16.8$ & $62.3 \pm 13.8$ & $62.5 \pm 13.1$ \\
\hline BMI, mean $\pm \mathrm{SD} \mathrm{kg} / \mathrm{m}^{2}$ & $28.3 \pm 4.6$ & $27.1 \pm 6.6$ & $30.5 \pm 5.0$ & $29.5 \pm 7.6$ \\
\hline $\mathrm{FEV}_{1}$, mean $\pm \mathrm{SD} \%$ predicted & $64.4 \pm 2.8$ & $64.8 \pm 2.9$ & $65.6 \pm 2.8$ & $65.2 \pm 3.1$ \\
\hline $\mathrm{FEV}_{1} / \mathrm{FVC}$, mean $\pm \mathrm{SD} \%$ & $61.1 \pm 4.7$ & $62.5 \pm 6.2$ & $74.0 \pm 4.8$ & $75.7 \pm 4.8$ \\
\hline \multicolumn{5}{|l|}{ Moderately severe impairment $\div$} \\
\hline Studies, no. & 61 & 58 & 75 & 77 \\
\hline Age, mean $\pm \mathrm{SD}$ y & $61.7 \pm 14.8$ & $64.9 \pm 10.3$ & $63.8 \pm 12.9$ & $64.3 \pm 11.7$ \\
\hline $\mathrm{BMI}$, mean $\pm \mathrm{SD} \mathrm{kg} / \mathrm{m}^{2}$ & $29.3 \pm 5.4$ & $27.6 \pm 5.8$ & $31.3 \pm 5.4$ & $30.1 \pm 9.7$ \\
\hline $\mathrm{FEV}_{1}$, mean $\pm \mathrm{SD} \%$ predicted & $55.6 \pm 3.0$ & $55.3 \pm 2.9$ & $55.7 \pm 2.8$ & $55.0 \pm 2.9$ \\
\hline $\mathrm{FEV}_{1} / \mathrm{FVC}$, mean $\pm \mathrm{SD} \%$ & $57.7 \pm 7.8$ & $59.1 \pm 6.7$ & $73.9 \pm 5.4$ & $74.6 \pm 5.6$ \\
\hline \multicolumn{5}{|l|}{ Severe impairment $\S$} \\
\hline Studies, no. & 93 & 77 & 44 & 30 \\
\hline Age, mean $\pm \mathrm{SD}$ y & $64.7 \pm 15.5$ & $64.7 \pm 11.9$ & $63.0 \pm 16.2$ & $63.3 \pm 14.5$ \\
\hline $\mathrm{BMI}$, mean $\pm \mathrm{SD} \mathrm{kg} / \mathrm{m}^{2}$ & $27.7 \pm 5.3$ & $27.6 \pm 8.0$ & $30.7 \pm 5.4$ & $30.3 \pm 9.6$ \\
\hline $\mathrm{FEV}_{1}$, mean $\pm \mathrm{SD} \%$ predicted & $42.3 \pm 3.9$ & $43.0 \pm 4.4$ & $45.2 \pm 3.6$ & $46.1 \pm 4.0$ \\
\hline $\mathrm{FEV}_{1} / \mathrm{FVC}$, mean $\pm \mathrm{SD} \%$ & $50.6 \pm 8.7$ & $51.8 \pm 8.1$ & $72.6 \pm 5.7$ & $75.1 \pm 5.4$ \\
\hline \multicolumn{5}{|l|}{ Very severe impairment $\|$} \\
\hline Studies, no. & 66 & 32 & 4 & 10 \\
\hline Age, mean \pm SD y & $59.3 \pm 18.7$ & $62.8 \pm 12.3$ & $68.3 \pm 6.6$ & $61.4 \pm 13.9$ \\
\hline $\mathrm{BMI}$, mean $\pm \mathrm{SD} \mathrm{kg} / \mathrm{m}^{2}$ & $26.1 \pm 5.7$ & $21.9 \pm 5.4$ & $32.6 \pm 3.6$ & $39.5 \pm 10.2$ \\
\hline $\mathrm{FEV}_{1}$, mean $\pm \mathrm{SD} \%$ predicted & $27.9 \pm 4.9$ & $29.2 \pm 4.8$ & $26.5 \pm 7.8$ & $29.7 \pm 3.7$ \\
\hline $\mathrm{FEV}_{1} / \mathrm{FVC}$, mean $\pm \mathrm{SD} \%$ & $43.3 \pm 9.3$ & $43.5 \pm 8.0$ & $74.2 \pm 5.4$ & $77.3 \pm 5.9$ \\
\hline $\begin{array}{l}\text { All the studies were categorized based on FEV } \\
* \text { Normal/mild category had an } \mathrm{FEV}_{1}(\% \text { predi } \\
\dagger \text { Moderate impairment ranged from } 60-70 \% \\
\text { \# Moderately severe impairment was from } 50- \\
\S \text { Severe impairment was } 35-50 \% \text { predicted. } \\
\| \text { Very severe FEV } \\
\text { BMI impairment had an } \mathrm{FEV}_{1} \\
\text { BMI = body mass index }\end{array}$ & sted in the $2005 \mathrm{In}$ & delines. ${ }^{6}$ & & \\
\hline
\end{tabular}

$2,710(53.0 \%)$ did not have obstruction when using either $\mathrm{FEV}_{1} / \mathrm{SVC}_{\text {or }} \mathrm{FEV}_{1} / \mathrm{FVC}$, whereas 566 of 2,710 (20.1\%) had an $\mathrm{FEV}_{1} / \mathrm{SVC}$, suggestive of obstruction with a normal $\mathrm{FEV}_{1} / \mathrm{FVC}$. A comparison between $\mathrm{FEV}_{1} / \mathrm{SVC}$ and $\mathrm{FEV}_{1} / \mathrm{FVC}$ was conducted by using an inter-rater reliability test with the inter-rater reliability kappa of 0.519 . Clinical characteristics of the 566 cases with obstructive lung disease based solely on $\mathrm{FEV}_{1} / \mathrm{SVC}$ are listed in Table 4. The majority had a smoking history (59.6\%), and nearly half carried a previous diagnosis of obstructive lung disease $(49.8 \%)$. Long-acting $\beta$-agonists, inhaled corticosteroids, and/or anticholinergics were prescribed to 345 of the subjects $(67.4 \%)$.

\section{Discussion}

There is recent evidence that those subjects with risk factors for obstructive lung disease and preserved lung function may have more exacerbations and health-care utilization costs than those without predisposing risk factors. ${ }^{8}$ Current PFT diagnostic algorithms exclude symptomatic, subjects at high risk with other evidence of obstructive disease. This single-center, retrospective PFT evaluation highlighted the large differences that can exist between the plethysmography-based SVC and the spirometry-based FVC maneuvers. We evaluated the difference between SVC 


\section{INCORPORATING SVC INTO PFTS}
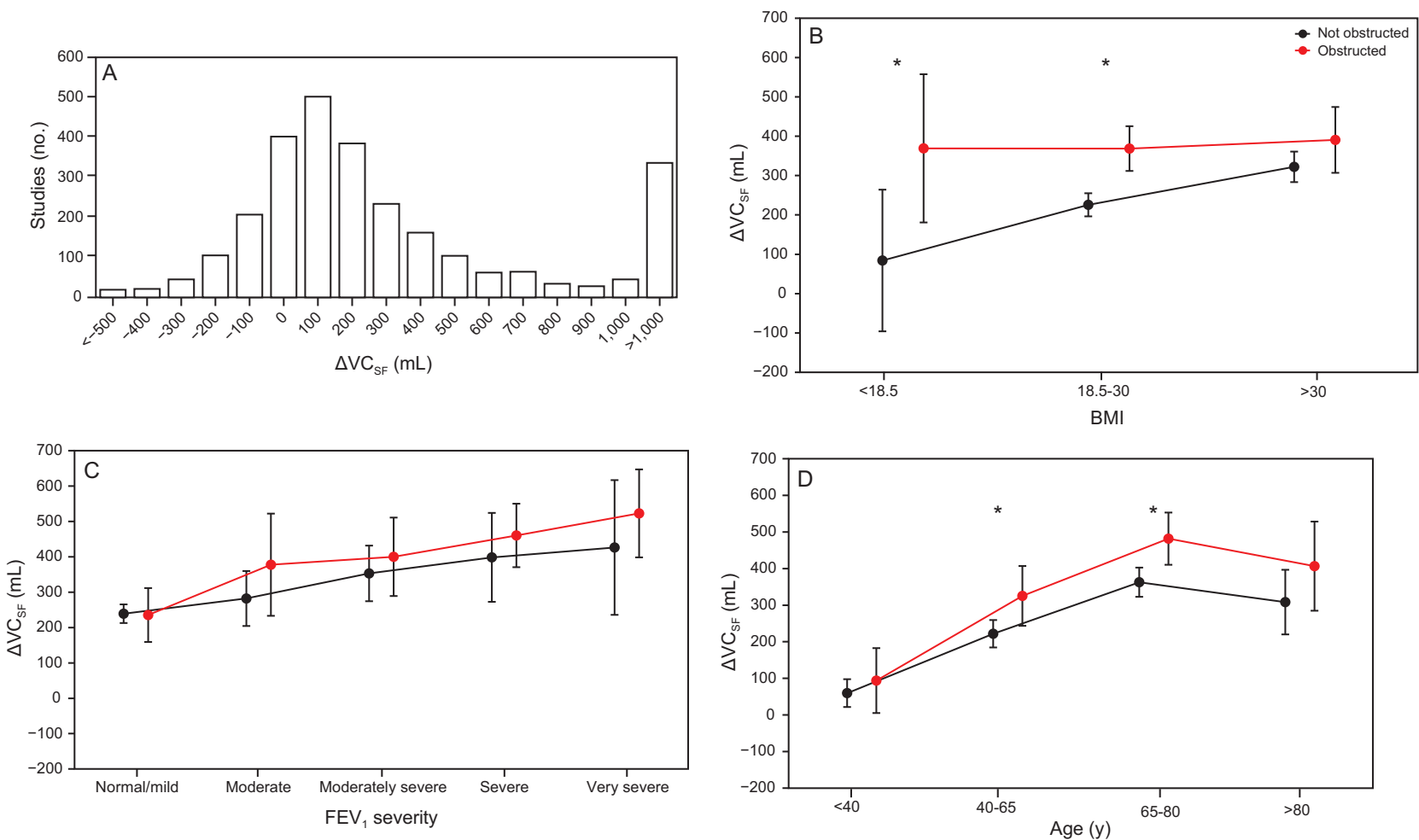

Fig. 1. A: Histogram, depicting the difference between slow vital capacity $(\mathrm{SVC})$ and $\mathrm{FVC}\left(\Delta \mathrm{VC}_{\mathrm{SF}}\right)$ over the entire cohort. Comparison of $\Delta \mathrm{VC}_{\mathrm{SF}}$ to body mass index (BMI) (B), $\mathrm{FEV}_{1}$ severity category (C), and age (D). Values represent mean $\pm \mathrm{SD}$. Statistically significant differences regarding delVC (SF) between those with obstruction based on $\mathrm{FEV}_{1} / \mathrm{FVC}$ and those without obstruction is depicted by $\left(^{\star}\right)$.

Table 3. Coefficients Derived From Multi-Variate Analysis for Calculation of Predictive Equation for the Difference Between SVC and FVC

\begin{tabular}{lcc}
\hline \hline \multicolumn{1}{c}{ Variable } & Parameter Estimate & $P$ \\
\hline Female* & -0.061 & $<.001$ \\
Age & 0.0046 & $<.001$ \\
Body mass index & 0.0072 & $<.001$ \\
FEV $_{1}(\mathrm{~mL})$ & -69.04 & $<.001$ \\
Presence of obstruction* & -0.032 & .02
\end{tabular}

All variables were statistically significan

* Female sex and the presence of obstruction (based on $\mathrm{FEV}_{1} / \mathrm{FVC}$ ) were incorporated by using " 0 " or " 1 ," based on the absence or presence of these conditions.

$\mathrm{SVC}=$ slow vital capacity

and FVC, and the incorporation of an $\mathrm{FEV}_{1} / \mathrm{SVC}_{\text {-based }}$ measurement.

The measurement of VC represents a complex and interdependent relationship among expiratory flow, intrathoracic airway, pleural, alveolar pressures, lung elastic recoil, and airway resistance. ${ }^{13} \mathrm{FVC} / \mathrm{SVC}$ has been proposed to detect small airway disease. This difference has been considered a potential marker of air-trapping and hyperinflation. ${ }^{14}$ Previous guidelines suggest an expected difference of 90-200 mL between FVC and SVC maneuvers in a selected reference population. ${ }^{4}$ Results of a few stud-
Table 4. Clinical Characteristics of Studies With Obstruction Based on $\mathrm{FEV}_{1} / \mathrm{SVC}$ but Without an $\mathrm{FEV}_{1} / \mathrm{FVC}$ Suggestive of Obstruction

\begin{tabular}{|c|c|}
\hline Characteristic & Value \\
\hline Subjects & 566 \\
\hline Males/females, $n$ & $304 / 262$ \\
\hline Age, mean \pm SD y & $60.8 \pm 15.0$ \\
\hline $\mathrm{BMI}$, mean $\pm \mathrm{SD} \mathrm{kg} / \mathrm{m}^{2}$ & $29.9 \pm 6.2$ \\
\hline \multicolumn{2}{|l|}{ Social characteristics } \\
\hline Current or former smokers, $n(\%)$ & $305(53.9)$ \\
\hline Pack-years, mean $\pm \mathrm{SD}$ & $35.7 \pm 28.9$ \\
\hline \multicolumn{2}{|c|}{ Pulmonary diagnosis based on EMR review, $n$} \\
\hline Asthma & 114 \\
\hline COPD & 141 \\
\hline \multicolumn{2}{|l|}{ Treatment of obstructive lung disease, $n$} \\
\hline Short-acting $\beta$-agonist & 337 \\
\hline Long-acting $\beta$-agonist & 188 \\
\hline Inhaled corticosteroid & 216 \\
\hline Inhaled anticholinergic & 144 \\
\hline $\begin{array}{l}\text { Any OLD therapy (except short-acting } \\
\beta \text {-agonist), } n(\%)\end{array}$ & $345(67.4 \%$ \\
\hline \multicolumn{2}{|l|}{$\overline{\text { SVC }=\text { slow vital capacity }}$} \\
\hline \multicolumn{2}{|l|}{$\mathrm{BMI}=$ body mass index } \\
\hline \multicolumn{2}{|l|}{$\mathrm{EMR}=$ electronic medical record } \\
\hline
\end{tabular}


ies showed that larger VC differences in both subjects with asthma and subjects with COPD are associated with worse respiratory symptoms and decreased exercise tolerance $5,15,16$

The mechanism for the difference in VC volumes is unclear. Brusasco et $\mathrm{al}^{5}$ indicate that increased air-flow results in increased transmural pressures in peripheral airways and subsequent airway closure at higher volumes. O'Donnell et al ${ }^{17}$ theorized that increased airway compliance results in pulmonary relaxation and static lung hyperinflation. Quanjer et $\mathrm{al}^{4}$ found that heterogeneous gas compression resulted in the observed differences between FVC and SVC. Although the pathophysiology responsible for the difference remains under study, the recognition of the difference is important for accurate interpretation of PFTs.

Analysis of our data demonstrated a relationship between the difference between SVC and FVC and multiple variables. In all subgroup analyses, subjects with an $\mathrm{FEV}_{1} / \mathrm{FVC}$-based obstruction had a larger difference than those without obstruction; however, there was a sizable difference between SVC and FVC present, even in those individuals without obstruction. When compared with BMI, there seemed to be a linearly increasing the difference between SVC and FVC in the subjects without obstruction, compared with the constant difference between SVC and FVC present in subjects with obstruction. Both obstructed and non-obstructed subjects demonstrated an increasing difference between SVC and FVC with age and $\mathrm{FEV}_{1}$. When combined in a multi-variate analysis, these variables, along with sex, indicate that the difference between SVC and FVC is influenced by variables other than solely BMI. ${ }^{18}$

Hyatt et $\mathrm{al}^{9}$ noted an increase in the diagnosis of obstructive lung disease by $\sim 50 \%$, similar to several other studies across diverse ethnic groups. ${ }^{10,11}$ This study confirmed this observation, with an increased prevalence of obstructive lung disease from $26 \%$ with the use of FVC to $45 \%$ when applying $\mathrm{FEV}_{1} / \mathrm{SVC}$ criteria. Our study captured an additional 566 subjects who would be classified as having obstructive lung disease based on this measurement. The majority of these subjects were smokers treated with bronchodilators or had a diagnosis of obstructive lung disease but maintained a preserved $\mathrm{FEV}_{1} / \mathrm{FVC}$.

The physiologic correlation of the SVC measurements in diagnosing obstruction remains unknown. It could be hypothesized that the difference between SVC and FVC represents a type of air-trapping present, with only mild exertion, which potentially helps to explain the discrepancy regarding symptoms among subjects. However, critics of SVC-based algorithms have questioned the utility of a submaximum effort because this volume is not used in normal breathing and cited the bias associated with BMI.9,18 Alternative diagnostic criteria, such as $\mathrm{FEV}_{1} /$ Forced expiratory volume in six second and Forced expiratory volume in three seconds/FVC, have previously been suggested but likely rely on similar flow dynamics and elastic properties as $\mathrm{FEV}_{1} / \mathrm{FVC}$ measurements. ${ }^{19,20}$ Although the uncertainty regarding SVC to FVC difference remains present, recognition that these differences exist may improve diagnostic utility of PFTs.

Study limitations included demographics of $<1 \%$ Asians and a potential overestimation of our Hispanic population because previous demographics misidentified the Asian race as Hispanic. However, the exact amount of overestimation cannot be determined. In addition, our cohort represented only referred subjects, most commonly with symptoms, which may have biased our VC difference measurements. Other limitations included the use of plethysmography to measure SVC rather than spirometric-based measurements, a failure to normalize SVC to FVC difference for common demographic markers (eg, age, height, and sex) and the lack of robust SVC-based reference equations.

Conventional teaching suggests that SVC is larger than FVC, albeit with small differences, whereas analysis of our data demonstrated select cases with FVC that were larger than SVC was present in subjects in select cases. These results were similar to those previously noted by Fortis et al, ${ }^{18}$ who postulated that the negative difference between SVC and FVC was secondary to the inspiratory reserve volume difference associated with BMI. Although a specific alternative mechanism for negative difference between SVC and FVC may be based on altered flow dynamics in those with a more depressed $\mathrm{FEV}_{1}$, which resulted in more-proximal obstruction during maneuvers of increased intrathoracic pressure. Comparatively, in individuals without obstruction or with mild $\mathrm{FEV}_{1}$ impairment, the increased intrathoracic pressure may serve to expel air from more distal alveoli with greater force, while also stenting open airways to allow for larger flow volumes during forced maneuvers. Alternatively, the negative difference between SVC and FVC may represent a testing error from using 2 separate methods of measuring VC: spirometry and plethysmography. ${ }^{18}$

\section{Conclusions}

The routine use of SVC to FVC difference or $\mathrm{FEV}_{1} / \mathrm{SVC}$ may offer improved identification of subjects with obstructive lung disease. The current use of only FVC-based diagnostic algorithms underdiagnose individuals with milder disease and individuals in whom increased intrathoracic pressure truncates the FVC measurement. Although the clinical implementation of SVC-based diagnostic criteria requires additional studies, recognition of differences between FVC and SVC may allow for earlier detection of disease and improved treatment outcomes. 


\section{INCORPORATING SVC INTO PFTS}

\section{REFERENCES}

1. Vogelmeier CF, Criner GJ, Martinez FJ, Anzueto A, Barnes P, Bourbeau $\mathrm{J}$, et al. Global strategy for the diagnosis, management and prevention of chronic obstructive lung disease 2017 report. Respirology 2017;22(3):575-601.

2. Standardization of spirometry, 1994 update. American Thoracic Society. Am J Respir Crit Care Med 1995;152(3):1107-1136.

3. Constán EG, Medina JP, Silvestre AH, Alvarez II, Olivas RB. Difference between the slow vital capacity and forced vital capacity: predictor of hyperinflation in patients with airflow obstruction. Internet J Pulm Med 2005;4(2):1.

4. Quanjer PH, Tammeling GJ, Pederson OJ, Peslin R, Yernault JC. Standardized lung function testing: report; official statement of the European Respiratory Society 1993. Eur Respir J 1993;6:5-40.

5. Brusasco V, Pellegrino R, Rodarte JR. Vital capacities in acute and chronic airway obstruction: dependence on flow and volume histories. Eur Respir J 10(6):1316-1320.

6. Pellegrino R, Viegi G, Brusasco V, Crapo RO, Burgos F, Casaburi $\mathrm{R}$, et al. Interpretative strategies for lung function tests. Eur Respir J 2005;26(5):948-968.

7. Dransfield MT, Kunisaki KM, Strand MJ, Anzueto A, Bhatt SP, Bowler RP, et al.; COPDGene Investigators. Acute exacerbations and lung function loss in smokers with and without chronic obstructive pulmonary disease. Am J Respir Crit Care Med 2017;195(3): 324-330.

8. Woodruff PG, Barr RG, Bleecker E, Christenson SA, Couper D, Curtis JL, et al.; SPIROMICS Research Group. Clinical significance of symptoms in smokers with preserved pulmonary function. N Engl J Med 2016;374(19):1811-1821.

9. Hyatt RE, Cowl CT, Bjoraker JA, Scanlon PD. Conditions associated with an abnormal nonspecific pattern of pulmonary function tests. Chest 2009;135(2):419-424.

10. Torén K, Olin AC, Lindberg A, Vikgren J, Schiöler L, Brandberg J, et al. Vital capacity and COPD: the Swedish CArdioPulmonary bio-
Image Study (SCAPIS). Int J Chron Obstruct Pulmon Dis 2016;11: 927-933.

11. Barros AR, Pires MB, Raposo NM. Importance of slow vital capacity in the detection of airway obstruction. J Bras Pneumol 2013; 39(3):317-322.

12. Hankinson JL, Odencrantz JR, Fedan KB. Spirometric reference values from a sample of the general U.S. population. Am J Respir Crit Care Med 1999;159(1):179-187.

13. Gagnon P, Guenette JA, Langer D, Laviolette L, Mainguy V, Maltais F, et al. Pathogenesis of hyperinflation in chronic obstructive pulmonary disease. Int J Chron Obstruct Pulmon Dis 2014;9(Can't get issue from record):187-201.

14. O'Donnell DE, Revill SM, Webb KA. Dynamic hyperinflation and exercise intolerance in chronic obstructive pulmonary disease. Am J Respir Crit Care Med 2001;164(5):770-777.

15. Chhabra SK. Forced vital capacity, slow vital capacity, or inspiratory vital capacity: which is the best measure of vital capacity? J Asthma 1998;35(4):361-365.

16. Yuan W, He X, Xu QF, Wang HY, Casaburi R. Increased difference between slow and forced vital capacity is associated with reduced exercise tolerance in COPD patients. BMC Pulm Med 2014;14:16.

17. O'Donnell DE, Banzett RB, Carrieri-Kohlman V, Casaburi R, Davenport PW, Gandevia SC, et al. Pathophysiology of dyspnea in chronic obstructive pulmonary disease: a roundtable. Proc Am Thorac Soc 2007;4(2):145-168.

18. Fortis S, Corazalla EO, Wang Q, Kim HJ. The difference between slow and forced vital capacity increases with increasing body mass index: a paradoxical difference in low and normal body mass indices. Respir Care 2015;60(1):113-118.

19. Bhatt SP, Kim YI, Wells JM, Bailey WC, Ramsdell JW, Foreman MG, et al. FEV(1)/FEV(6) to diagnose airflow obstruction. Comparisons with computed tomography and morbidity indices. Ann Am Thorac Soc 2014;11(3):335-341.

20. Morris ZQ, Coz A, Starosta D. An isolated reduction of the FEV3/FVC ratio is an indicator of mild lung injury. Chest 2013; 144(4):1117-1123. 